\title{
Higher central fat and poor self-body image in short-stature overweight/obese women living in Brazilian shantytowns
}

\author{
Nassib Bezerra Bueno ${ }^{\text {Corresp.., }}{ }^{1}$ ， Telma Toledo Florêncio ${ }^{1}$ ， Fabiana Albuquerque Cavalcante ${ }^{1}$, Isabela Lopes Lins \\ 1, Ana Grotti Clemente ${ }^{1}$, Ana Lydia Sawaya ${ }^{2}$ \\ 1 Faculdade de Nutrição, Universidade Federal de Alagoas, Maceió, AL, Brazil \\ 2 Departamento de Fisiologia, Universidade Federal de São Paulo, São Paulo, SP, Brazil \\ Corresponding Author: Nassib Bezerra Bueno \\ Email address: nassibbb@hotmail.com
}

Background: Short stature in adult life, a possible consequence of poor perinatal conditions, is associated with higher risk of mortality and social disabilities. We aimed to determine whether low-income, overweight/obese, short-stature (SS) women show alterations in body composition, self-body-image perception, and biochemical profile compared to their non-short (NS) counterparts. Methods: A cross-sectional study was conducted with women living in shantytowns and mother or relatives to undernourished children treated in a center for recuperation and nutritional education. Inclusion criteria were: (1) age, 19-45 years; (2) stature $<152.3 \mathrm{~cm}$ or $>158.7 \mathrm{~cm}$; and (3) body mass index $>25 \mathrm{~kg} / \mathrm{m}^{2}$. Socioeconomic, anthropometric, biochemical, and body image data were collected. We analyzed 56 SS and 57 NS women. Results: The SS group showed a higher waist-to-height ratio (mean: 0.63; standard deviation: 0.06 for SS and mean: 0.60; standard deviation: 0.07 for the NS group; $p=0.02$ ), and, in the adjusted analysis, showed lower fat-free mass (Estimated Marginal Mean for the SS group: $45.7 \mathrm{~kg} 95 \% \mathrm{Cl}$ [45.2 46.2] and for the NS group: $46.9 \mathrm{~kg} \mathrm{95 \% Cl} \mathrm{[46.4-47.4];} \mathrm{p}<0.01$ ) and higher fat mass (Estimated Marginal Mean for the SS group: $32.595 \% \mathrm{Cl}$ [31.9 - 33.0] and for the NS group:

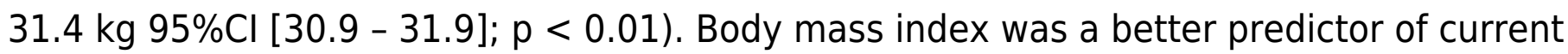
self-body-image perception for NS women. The SS coefficient values were $\beta=0.141, S E=$ 0.059 , and $R^{2}$-Nagelkerke $=0.107$, and the NS coefficients values were $\beta=0.307, S E=$ 0.058 , and $\mathrm{R}^{2}$-Nagelkerke $=0.491(Z=2.006 ; p<0.05)$. Considering the obese subgroup, 6 out of 32 (18.8\%) SS women and 14 out of 33 (42.4\%) NS women perceived themselves as obese $\left(\chi^{2}=4.27 ; p=0.03\right)$. This difference remained significant even after adjustment by age, schooling, and number of children $(p=0.04)$. Only the total thyroxin showed significant differences between groups, lower in SS women $(p=0.04)$. Discussion: Overweight/obese, low-income SS women have more central adiposity and impaired selfbody image perception, and the body mass index is a weaker predictor of it, compared to 
NS women. Misperception about body size may be linked with an overestimation of health and underestimation of risk, which may lead to a lower utilization of the health care system and inadequate physician counseling. These features may account, at least partially, for the higher mortality risk seen in SS adults. 
1 Higher central fat and poor self-body image in short-stature overweight/obese women

2 living in Brazilian shantytowns

3

4 Nassib Bezerra Bueno ${ }^{1 *}$, Telma Toledo Florêncio ${ }^{1}$, Fabiana Albuquerque Cavalcante ${ }^{1}$, Isabela

5 Lopes Lins ${ }^{1}$, Ana Grotti Clemente ${ }^{1}$, Ana Lydia Sawaya ${ }^{2}$

6

$7{ }^{1}$ Centro de Recuperação e Educação Nutricional, Faculdade de Nutrição, Universidade Federal

8 de Alagoas, Maceió-AL, Brazil.

$9 \quad{ }^{2}$ Laboratório de Fisiologia da Nutrição, Departamento de Fisiologia, Universidade Federal de

10 São Paulo-SP, Brazil.

11

$12 *$ Corresponding author

13 Nassib B Bueno ${ }^{1}$

14 E-mail: nassibbb@hotmail.com

15

16 


\section{Abstract}

18 Background: Short stature in adult life, a possible consequence of poor perinatal conditions, is associated with higher risk of mortality and social disabilities. We aimed to determine whether low-income, overweight/obese, short-stature (SS) women show alterations in body composition, self-body-image perception, and biochemical profile compared to their non-short (NS) counterparts.

Methods: A cross-sectional study was conducted with women living in shantytowns and mother or relatives to undernourished children treated in a center for recuperation and nutritional education. Inclusion criteria were: (1) age, 19-45 years; (2) stature $<152.3 \mathrm{~cm}$ or $>158.7 \mathrm{~cm}$; and (3) body mass index $>25 \mathrm{~kg} / \mathrm{m}^{2}$. Socioeconomic, anthropometric, biochemical, and body image data were collected. We analyzed 56 SS and 57 NS women.

Results: The SS group showed a higher waist-to-height ratio (mean: 0.63; standard deviation: 0.06 for SS and mean: 0.60 ; standard deviation: 0.07 for the NS group; $p=0.02$ ), and, in the adjusted analysis, showed lower fat-free mass (Estimated Marginal Mean for the SS group: 45.7 $\operatorname{kg} 95 \% \mathrm{CI}[45.2-46.2]$ and for the NS group: $46.9 \mathrm{~kg} 95 \% \mathrm{CI}[46.4-47.4] ; \mathrm{p}<0.01)$ and higher fat mass (Estimated Marginal Mean for the SS group: 32.5 95\%CI [31.9 - 33.0] and for the NS group: $31.4 \mathrm{~kg} 95 \% \mathrm{CI}[30.9$ - 31.9]; $\mathrm{p}<0.01$ ). Body mass index was a better predictor of current self-body-image perception for NS women. The SS coefficient values were $\beta=0.141, S E$ $=0.059$, and $\mathrm{R}^{2}$-Nagelkerke $=0.107$, and the NS coefficients values were $\beta=0.307, S E=0.058$, and $\mathrm{R}^{2}$-Nagelkerke $=0.491(Z=2.006 ; \mathrm{p}<0.05)$. Considering the obese subgroup, 6 out of 32

$37(18.8 \%)$ SS women and 14 out of $33(42.4 \%)$ NS women perceived themselves as obese $\left(\chi^{2}=\right.$ 38 4.27; $\mathrm{p}=0.03$ ). This difference remained significant even after adjustment by age, schooling, 
39 and number of children $(\mathrm{p}=0.04)$. Only the total thyroxin showed significant differences

40 between groups, lower in SS women $(p=0.04)$.

41 Discussion: Overweight/obese, low-income SS women have more central adiposity and impaired

42 self-body image perception, and the body mass index is a weaker predictor of it, compared to NS

43 women. Misperception about body size may be linked with an overestimation of health and

44 underestimation of risk, which may lead to a lower utilization of the health care system and

45 inadequate physician counseling. These features may account, at least partially, for the higher

46 mortality risk seen in SS adults. 


\section{Introduction}

Studies on the developmental origins of health and disease aim to understand how events

in early life shape the morbidity risk later in life (Gluckman, Hansona \& Buklijasa, 2010). As non-communicable chronic diseases are currently one of the major causes of morbidity and mortality worldwide and their prevalence is currently increasing, the number of studies being conducted on this topic has also been increasing. Poor health in the early stages of life may be responsible for long-term social and metabolic/morphologic consequences (Victora et al., 2008) and is responsible for the intergenerational transmission of inequality, where disadvantaged parents give birth to disadvantaged children who will probably be disadvantaged parents in the future (Aizer \& Currie, 2014).

Adult short stature is a direct consequence of impaired early growth caused by poor health, particularly inadequate nutrition and recurrent infections (Shrimpton et al., 2001). It is possible to attenuate adult short stature with compensatory growth during childhood. However, in low- and middle-income countries, people tend to remain in the setting in which they developed childhood undernutrition, leading to poor compensation of growth failure and, ultimately, the children grow into short adults (Martorell, Khan \& Schroeder 1994). An analysis of a Brazilian birth cohort showed that women who had a height-for-age $Z$ score at 2 years lower than -3 , presented an attained height of approximately $146 \mathrm{~cm}$ in adulthood, in contrast with 163 cm presented by those who had a height-for-age Z score greater than -1 (Victora et al., 2008). .Additionally, in the analysis of five birth cohorts in developing countries, stunted children were more likely to have a reduced lean body mass, attain a lower education level, and have reduced earnings in adulthood (Victora et al., 2008). 

patient meta-analysis of more than 16.1 million person/year showed that the risk of all-cause mortality is $3 \%$ lower per $6.5 \mathrm{~cm}$ height in adult life, although disaggregation by cause-specific mortality revealed stronger and directionally opposing relationships with the risk of death from different major causes of chronic disease. The study concluded that taller people have a lower risk of death from coronary disease, stroke subtypes, heart failure, oral and gastric cancers, chronic obstructive pulmonary disease, mental disorders, liver diseases, and external causes (Emerging Risk Factor Collaboration et al., 2012).

An overweight/obese short-statured adult will be at a great risk of chronic disease, especially cardiovascular diseases. Women in a low-income region from a developing country that is facing a nutrition transition are especially at risk owing to persistent weight gain due to low energy expenditure, working at home, and hyperenergetic diets (Kanter \& Caballero, 2012). This is a common situation in Brazilian northeast. fully understood, especially in the context of a low-income setting. Hence, the present study aimed to determine whether overweight/obese SS women from Maceió, capital city of the state of Alagoas, and one of the poorest capital city of Brazil, show any alterations in their body composition, self-body-image perception, and blood biochemical profile as compared to their non-short (NS) counterparts.

\section{Methods}


Data were collected from all participants after they provided written informed consent.

92

93

94

95

96

97

98

\section{Study design and subjects}

This was a cross-sectional study of women living in a shantytown in Maceió-AL, Brazil. The subjects were mothers and/or female relatives of undernourished children who attended the Centre for Recuperation and Nutritional Education (CREN/Maceió), an extension of the Federal University of Alagoas that treats undernourished children with a goal of improving their nutritional status.

We investigated two different groups: SS women and NS women. Inclusion criteria were as follows: (i) age, 19-45 years; (ii) stature $\leq 152.3 \mathrm{~cm}$ (5th percentile of the World Health Organization growth curves) (SS group) or $>158.7 \mathrm{~cm}$ (25th percentile) (NS group) (World Health Organization, 2007); and (iii) a body mass index (BMI) $>25 \mathrm{~kg} / \mathrm{m}^{2}$. Pregnant and lactating women and those taking chronic medication, insulin, and antiretrovirals) were not included.

We used a non-probability convenience sampling approach, inviting all mothers and relatives of the undernourished children treated at CREN to a screening at the center. All included women were then invited to join a behavioral weight-loss program.

\section{Data collection}

Data were collected at CREN with a previously tested and structured protocol regarding personal, socioeconomic, and demographic information such as age, years of schooling, 
114 occupation, household conditions, and number of family members, wage, government benefits, 115 precedence (city or rural).

116 Anthropometric measurements (body weight, stature, and waist and hip circumferences)

117 were obtained from all participants while they were wearing light clothing without shoes. Body

118 weight was determined using electrical bioimpedance with Tanita Body Fat analyzer (model

119 TBF-300; Tanita Corporation of America, Inc., Arlington Heights, IL), which also measured fat 120 mass, fat-free mass, and body fat percentage and calculated the basal metabolic rate (BMR). To

121 measure the stature, the women were asked to stand in the full upright position using a portable

122 stadiometer, which was equipped with an inextensible metric tape marked by $0.1-\mathrm{cm}$

123 graduations. Waist circumference (WC) was measured during a normal expiration, using an

124 inextensible flexible metric tape at the umbilical point. Hip circumference was measured at the

125 point yielding the maximum circumference over the buttocks. The waist-to-hip ratio (WHR) and

126 waist-to-height ratio (WHtR) were also calculated by dividing the WC by the hip circumference,

127 and the WC for the height in centimeters, respectively. Body surface area was calculated

128 according to method used by Mosteller (1987). Blood pressure was measured on three

129 consecutive occasions using calibrated monitors against mercury manometers (Model HEM-421-

130 CO, Amsterdam, Netherlands) by the standard technique, with individuals being seated and

131 relaxed.

132 To measure body image, a scale consisting of 9 female figures, ranging from very thin to

133 very obese (figures 1-9), was used (Stunkard, 2000). Participants were asked to choose one

134 figure that, in their opinion, currently represented their body and one that represented their ideal

135 body. The discrepancy score was calculated by subtracting the ideal self-body image number

136 from the current self-body image number. These figures were classified into underweight 
137 (figures 1 and 2), normal weight (figures 3 and 4), overweight (figures 5 through 7), and obese

138 (figures 8 and 9), according to the method of Lynch et al. (2009). This scale has already been

139 translated into Portuguese and tested with Brazilian women (Scagliusi et al., 2006).

140 Blood samples were collected at CREN facilities for biochemical profile studies. Women

141 were instructed to fast overnight before undergoing venous puncture. Tests for the following

142 parameters were performed: blood glucose and insulin, Homeostasis Model Assessment for

143 insulin resistance (HOMA-IR), $\beta$-cell function (HOMA- $\beta$ ), total cholesterol, high-density

144 lipoprotein, low-density lipoprotein, triacylglycerols, aspartate amino-transferase, alanine amino-

145 transferase, gamma-glutamyl transpeptidase, thyroid-stimulating hormone, triiodothyronine,

146 thyroxin, albuminuria, and cystatin-C.

148 Statistical analysis

149 Continuous and discrete data are presented as mean and standard deviation and 150 categorical data, as absolute and relative frequency. For all continuous variables, the normality

151 and variance's homogeneity assumptions were tested by the Lilliefors' and Levene's tests. When

152 the assumptions were met, Student $t$-tests were conducted; otherwise, Welch's t-tests were

153 conducted. Discrete variables were subjected to Mann-Whitney tests. Categorical variables were

154 compared using the $\chi^{2}$ test or Fisher Exact test, when appropriate. Multivariate analysis with

155 dichotomous outcomes were performed by means of logistic regression.

156 Variables that could be influenced by body size (such as fat mass and lean mass) were

157 subjected to an analysis of covariance (ANCOVA) using body weight and age as covariates, and

158 the estimated marginal means (EMM) and 95\% confidence intervals (CI) were calculated. An

159 ordinal regression was performed using current self-body-image perception as the dependent 
160 variable and BMI as the independent variable for each subgroup (NS and SS). Further, regression

161 coefficients were compared by Fisher's Z-test. In addition, a full ordinal regression model

162 including confounders and an interaction term between height and BMI was designed. For all

163 analyses, a two-tailed approach was adopted, and alpha was set at 5\%. For the statistical

164 analyses, SPSS v20.0 (IBM statistics, Chicago, IL) was used.

165

166

167

168

169

170

171

172

173

174

175

176

177

178

179

180

181

182

\section{Results}

At total, 262 women were invited to the screening, comprising all mothers and relatives of the undernourished children treated at CREN. From these, 149 were not included in our analysis: 116 did not meet inclusion criteria for age, height and/or body mass index; 15 were pregnant or lactating; 5 were taking insulin; and 13 refused to participate. A total of 113 women were finally included in the analyses. Of these, 57 were NS and 56 were SS women. Socioeconomic characteristics of the population are shown in Table 1. In general, the SS group received less schooling, had more children, and were more likely to arise from rural areas. The others variables did not show any significant differences.

Table 2 presents the women's anthropometric and self-body image assessments. The NS group had significant higher values for body size variables, except WC, which did not show any significance, and WHtR, which was higher in the SS group, indicating a central-obesity profile.

Table 3 shows the adjusted analysis for the between-group comparison for fat mass, lean mass, body fat percentage and basal metabolic rate, including body weight as a covariate in the model. In this case, the variables for body composition showed opposite results as those of the unadjusted analysis, shown in Table 2, that is, according to the EMM of the adjusted analysis, SS women showed lower lean mass, and higher fat mass. These differences between groups were 
183 significant (Table 3). Results of the biochemical and blood pressure analyses are presented in

184 Table 4. Only a small difference in the total thyroxin level was noted, and the SS group showed 185 lower values than the NS group.

186 Although the self-body-image assessment did not show any significant differences

187 between groups, ordinal regression analysis showed that BMI is a significant better predictor of 188 current self-body-image perception for NS women than for SS women (Figure 1). The SS

189 coefficient values were $\beta=0.141, S E=0.059$, and $\mathrm{R}^{2}$-Nagelkerke $=0.107$, and the NS

190 coefficients values were $\beta=0.307, S E=0.058$, and $\mathrm{R}^{2}$-Nagelkerke $=0.491(Z=2.006 ; \mathrm{p}<0.05)$.

191 In the full model, including age, schooling, and number of children, the interaction between BMI

192 and height category was also significant $(\mathrm{p}=0.018)$, showing that height category acts as an

193 effect moderator variable.

194 When considering only the obese subgroup, 6 out of $32(18.8 \%)$ SS women and 14 out of $19533(42.4 \%)$ NS women perceived themselves as obese based on the categorized score of the scale $196\left(\left(\chi^{2}=4.27 ; \mathrm{p}=0.03\right)\right.$. This difference remained significant even after adjustment by age,

197 schooling, and number of children $(p=0.04)$.

198 Using WHtR as main variable, with an alpha-value of 5\%, a mean standard deviation of 1990,065 and the sample size and means reported in the study, the post-hoc power for the 200 comparisons between groups was $68 \%$.

201

202 Discussion

203

As previously outlined, the mechanisms that lead to increased cardiovascular risks in SS

204 adults are not fully understood. Height is a biomarker that congregates the genetic endowment

205 and early-life experiences of the individuals (NCD Risk Factor Collaboration, 2016). Therefore, 
206 the increased risk presented by short adults could be due to morphologic aspects, such as smaller

207 coronary vessels diameter and/or faster heart rate (Smulyan et al., 1998). Nevertheless, as short-

208 stature in adult life is believed to reflect, at least in part, poor nutrition and socioeconomic

209 aspects in early-life, the possibility of a "metabolic programming" is plausible and accepted

210 nowadays as the theory of "developmental origins of health and disease" (Heindel et al., 2015).

211 This theory states that adverse events in early-life (that would impair growth and possibly lead to

212 short-stature in adult life) could contribute to increased risk of cardiovascular disease in

213 adulthood. In our cross-sectional study, we found that overweight/obese SS women had

214 relatively more fat mass and less lean mass than their non-short counterparts. In addition, the

215 BMI of short-statured women had significantly less power to predict their actual body image. We

216 believe that these features may account, at least partially, for the higher mortality risk seen in SS

217 adults.

218 Our two study groups were socially very similar to each other, except for their schooling,

219 number of children and precedence. In populations originating from rural areas, where the health

220 conditions are worse, delivery at home is usually expected, and it is likely that the mothers came

221 to the capital city looking for better life conditions, which is a common phenomenon in this

222 population. As a whole, Alagoas is a very poor Brazilian state. A probabilistic survey conducted

223 in 1992 showed that stunting levels among children were 22.1\% (Ferreira et al., 2013). These

224 levels were even higher in a survey with the rural population in 1995, reaching 39,8\% (Ferreira

225 et al., 1997). Hence, it is likely that our sample, specially the SS group, went through hazardous

226 conditions during early life.

227 Undernutrition early in life has been consistently linked with a lower educational level

228 (Gratham-McGregor et al., 2007). Lower education, in turn, is linked with household crowding 
229 (Melki et al., 2004), which we indirectly measured by the number of children in the household;

230 this is a known form of chronic stress that is detrimental to the psychological well-being (Fuller

231 et al., 1996). The increased adiposity noted in our study confirmed the trend reported by Lopez-

232 Alvarenga et al. (2003), although they had analyzed both men and women, and not all were

233 overweight/obese. Our finding is also in accordance with that of Martins et al. (2004) who

234 reported that stunted girls gained less lean mass and had a significantly higher fat mass at follow-

235 up than their baseline values. We analyzed body composition data by using an ANCOVA to

236 consider the differences in body size between groups, since NS women are significantly bigger

237 than SS women. We chose to use body weight as a covariate in the model because stature was

238 already considered as a fixed factor in the analysis (the subjects were grouped based on stature),

239 hence, using body surface area would use stature twice in the model.

240 Increased adiposity, which is associated with central obesity (Zhang et al., 2007), is a

241 well-known mortality risk for women and is of a greater risk to young women (Hu et al., 2004;

242 Lahmman et al., 2002). In our sample, we did not find any differences in the WHR between the

243 NS and SS groups, as was also reported by Florêncio et al. (2007). Nevertheless, we did find

244 differences in the WHtR, which is known to be as good as the other markers of central adiposity

245 that predicted cardiovascular events in women (Page et al., 2009) and a better marker than WHR

246 that predicted albuminuria in diabetic Chinese women (Tseng, 2005). Indeed, the utility of

247 WHR, although used widely, is questionable because individually, waist and hip circumferences

248 are known to have contrasting associations with mortality (Bigaard et al., 2004). In our sample,

249 although NS women had a significantly greater WC than SS women, when the WC values were

250 divided by stature, the NS women had a greater anthropometric advantage. Still regarding the

251 WC, as we measured it at the umbilical point, and not in the midpoint between iliac crest and 
252 lower rib, it is possible that the value of WC for some women, especially those with higher

253 adiposity were overestimated.

Florêncio et al. (2007) reported that overweight/obese SS women had a greater

255 prevalence of insulin resistance and altered lipid profile as compared to women with average

256 stature. However, we were unable to confirm these findings. Nevertheless, they assessed women

257 in a poorer socioeconomic status, older and with lower stature than ours. Interestingly, although

258 the level of thyroxin was lower in the SS group, no effects were seen in the levels of thyroid-

259 stimulating hormone even after log-transformation and removal of outliers. This lower thyroxin

260 level could explain the lower basal metabolic rate found in the adjusted analysis. However, when

261 considering the absence of differences in thyroid-stimulating hormone between groups, and the

262 fact that 18 metabolic markers were compared in our analysis, it is likely that the difference

263 found in thyroxin levels between groups is spurious.

264 Regarding self-body image, it is reasonable to state that the BMI is the best determinant

265 of the current self-body image perception (Kaufer-Horwitz et al., 2006). In our sample, BMI was

266 a significantly weaker predictor of current self-body image assessment in SS women as

267 compared to NS women, and this relationship remained significant even after correction for

268 possible confounding social variables. In addition, obese SS women were less likely to perceive

269 themselves as obese as compared to NS women.

270 Holdsworth et al. (2004) found that Senegalese women believed that being overweight

271 was socially preferred, but being obese was associated with a greater risk of disease. In a

272 longitudinal investigation, Lynch et al. (2009) found that obese women who did not perceive

273 themselves as obese gained more weight over a course of 13 years. Powell et al. (2010) showed

274 that misperception about body size is prevalent among obese adults, particularly among ethnic 
275 minorities. They emphasized that this phenomenon may be linked with an overestimation of

276 health and underestimation of risk, which may lead to a lower utilization of the health care

277 system and inadequate physician counseling. Taken together, all these issues could enhance the

278 risk of mortality among those with impaired self-body image in the long-term. It is possible that

279 SS women perceive themselves as small as compared to NS women. Since body weight is

280 possibly their parameter of choice to assess their body size, owing to its simplicity, they may not

281 perceive themselves as have "excess weight" when they weigh approximately $56 \mathrm{~kg}$, which is the

282 average weight for a 149-cm tall woman to be considered overweight.

283 This study has some limitations. First, we used a non-probabilistic convenience sample,

284 which decreases our ability to extrapolate our findings. Second, we used bioimpedance analysis

285 to assess body composition, which is not a gold standard method, such as deuterium. Third, we

286 used a single scale to assess body image, which may weaken our findings regarding this

287 characteristic.

288

289 Conclusions

290 In conclusion, the present study showed that overweight/obese, shantytown-dwelling SS

291 women present with more central adiposity and impaired self-body image perception than NS

292 women, and BMI is a weaker predictor of current self-body-image perception. These findings

293 could partially explain the higher mortality rates found in SS adults. Further longitudinal

294 investigations, assessing these characteristics in mortality or cardiovascular events are needed. 


\section{References}

298 Aizer A, Currie J. The intergenerational transmission of inequality: Maternal disadvantage and 299 health at birth. Science. 2014; 344: 856. DOI: 10.1126/science.1251872

300

301

302

Bigaard J, Frederiksen K, Tjonneland A, Thomsen BL, Overvad K, Heitmann BL, Sorensen

TI. Waist and hip circumferences and all-cause mortality: usefulness of the waist-to-hip ratio? Int

J Obes Relat Metab Disord. 2004; 28: 741-747.

304

305

Emerging Risk Factors Collaboration. Adult height and the risk of cause-specific death and

vascular morbidity in 1 million people: individual participant meta-analysis. Int J Epidemiol.

307

2012; 41(5): 1419-33. doi: 10.1093/ije/dys086.

308

309

Ferreira HS, Albuquerque MF, Ataide TR, Morais MG, Mendes MC, Siqueira TC, Silva

310

GJ. Estado nutricional de crianças menores de dez anos residentes em invasão do "Movimento dos Sem-Terra", Porto Calvo, Alagoas. Cad. Saúde Pública. 1997; 13(1): 137-139

312

313

Ferreira, HS, Cesar, JA, Assunção, ML, Horta, BL. Time trends (1992-2005) in undernutrition and obesity among children under five years of age in Alagoas State, Brazil. Cad. Saúde Pública. 2013; 29(4): 793-800.

316

317 Florêncio TT, Ferreira HS, Cavalcante JC, Stux GR, Sawaya AL. Short stature, abdominal 318 obesity, insulin resistance and alterations in lipid profile in very low-income women living in 319 Maceió, north-eastern Brazil. Eur J Cardiovasc Prev Rehabil. 2007; 14(2): 346-8. 
321 Fuller TD, Edwards JN, Vorakitphokatorn S, Sermsri S. Chronic stress and psychological well-

322 being: evidence from Thailand on household crowding. Soc Sci Med. 1996; 42(2): 265-80.

323

324 Gluckman PD, Hansona MA, Buklijasa T. A conceptual framework for the developmental 325 origins of health and disease. J Dev Orig Health Dis. 2010; 1(1): 6-18.

326

327 Grantham-McGregor S, Cheung Y, Cueto S, Glewwe P, Richter L, Strupp L. Developmental 328 potential in the first 5 years for child in developing countries. Lancet. 2007; 369: 60-70.

Heindel JJ, Balbus J, Birnbaum L, Brune-Drisse MN, Grandjean P, Gray K, Landrigan PJ, Sly

PD, Suk W, Cory Slechta D, Thompson C, Hanson M. Developmental Origins of Health and

Disease: Integrating Environmental Influences. Endocrinology. 2015 Oct;156(10):3416-21. doi:

Holdsworth M, Gartner A, Landais E, Maire B, Delpeuch F. Perceptions of healthy and desirable body size in urban Senegalese women. Int J Obes Relat Metab Disord. 2004; 28(12): 1561-8. physical activity in predicting mortality among women. N Engl J Med. 2004; 351(26): 2694-703.

341 Kanter R, Caballero B. Global gender disparities in obesity: a review. Adv Nutr. 2012; 3(4): 4918. doi: 10.3945/an.112.002063. 
344 Kaufer-Horwitz M, Martínez J, Goti-Rodríguez LM, Avila-Rosas H. Association between

345 measured BMI and self-perceived body size in Mexican adults. Ann Hum Biol. 2006; 33(5-6):

$346 \quad 536-45$.

347

348 Lahmann PH., Lissner L, Gullberg B, Berglund G. A Prospective Study of Adiposity and All-

349 Cause Mortality: The Malmö Diet and Cancer Study. Obes Res. 2002; 10: 361-369. doi:

$350 \quad 10.1038 /$ oby.2002.50

351

352

López-Alvarenga JC, Montesinos-Cabrera RA, Velázquez-Alva C, González-Barranco J. Short

353

stature is related to high body fat composition despite body mass index in a Mexican population.

354 Arch Med Res. 2003; 34(2): 137-40.

355

356

Lynch E, Liu K, Wei GS, Spring B, Kiefe C, Greenland P. The Relation Between Body Size

Perception and Change in Body Mass Index Over 13 Years The Coronary Artery Risk

358

Development in Young Adults (CARDIA) Study. Am J Epidemiol. 2009; 169(7): 857-66.

359

360

Martins PA, Hoffman DJ, Fernandes MT, Nascimento CR, Roberts SB, Sesso R, Sawaya AL.

361

Stunted children gain less lean body mass and more fat mass than their non-stunted counterparts:

362 a prospective study. Br J Nutr. 2004; 92(5): 819-25.

363

364

Martorell R, Khan LK, Schroeder DG. Reversibility of stunting: epidemiological findings in

365 children from developing countries. Eur J Clin Nutr 1994; 48 (suppl 1): S45-57. 
367 Melki IS, Beydoun HA, Khogali M, Tamim H, Yunis KA. Household crowding index: a

368 correlate of socioeconomic status and inter-pregnancy spacing in an urban setting. J Epidemiol

369 Commun H. 2004; 58(6): 476-480.

370

371 Mosteller RD. Simplified Calculation of Body Surface Area. N Engl J Med. 1987; 317(17):

3721098.

373

374 Page JH, Rexrode KM, Hu F, Albert CM, Chae CU, Manson JE. Waist-height ratio as a predictor 375 of coronary heart disease among women. Epidemiol. 2009; 20(3): 361-6.

376

377 NCD Risk Factor Collaboration (NCD-RisC). A century of trends in adult human height. Elife. 3782016 Jul 26;5. pii: e13410. doi: 10.7554/eLife.13410.

379

380

Powell TM, de Lemos JA, Banks K, Ayers CR, Rohatgi A, Khera A, McGuire DK, Berry JD,

Albert MA, Vega GL, Grundy SM, Das SR . Body size misperception: a novel determinant in the 382 obesity epidemic. Arch Intern Med. 2010; 170(18): 1695-7. doi:

10.1001/archinternmed.2010.314.

384

Scagliusi FB, Alvarenga M, Polacow VO, Cordás TA, de Oliveira Queiroz GK, Coelho D, 386 Philippi ST, Lancha AH Jr. Concurrent and discriminant validity of the Stunkard's figure rating scale adapted into Portuguese. Appetite. 2006; 47(1): 77-82. 
389 Shrimpton R, Victora CG, de Onis M, Lima RC, Blossner M, Clugston G. Worldwide timing of 390 growth faltering: implications for nutritional interventions. Pediatrics 2001; 107: E75.

391

392 Smulyan H, Marchais SJ, Pannier B, Guerin AP, Safar ME, London GM. Influence of body 393 height on pulsatile arterial hemodynamic data. J Am Coll Cardiol 1998; 31:1103-9.

Stunkard A. Old and new scales for the assessment of body image. Perceptual and Motor Skills. 396 2000; 90: 930.

397

Tseng C. Waist-to-height ratio is independently and better associated with urinary albumin excretion rate than waist circumference or waist-to-hip ratio in Chinese adult type 2 diabetic 400 women but not men. Diabetes Care. 2005; 28(9): 2249-2251 doi:10.2337/diacare.28.9.2249

401

402

Victora CG., Adair L, Fall C, Hallal PC, Martorell R, Richter L. Sachdev HS, Maternal and 403 Child Undernutrition Study Group. Maternal and child undernutrition: consequences for adult 404 health and human capital. Lancet. 2008; 371: 340-357.

405

406

World Health Organization. Growth reference data for 5-19 years. 2007. Available at:

407 http://www.who.int/growthref/hfa_girls_5_19years_per.pdf

408

409

Zhang X, Shu XO, Yang G, Li H, Cai H, Gao YT, Zheng W. Abdominal adiposity and mortality 410 in Chinese women. Arch Intern Med. 2007; 167(9): 886-92.

411 


\section{Table 1 (on next page)}

Socioeconomic Characteristics of the Sample $(n=113)$

${ }^{1}$ Results expressed as mean and standard deviation. ${ }^{2}$ Results expressed as absolute and relative frequency. 
1 Table 1. Socioeconomic Characteristics of the Sample $(n=113)$

\begin{tabular}{|c|c|c|c|c|c|}
\hline \multirow[t]{2}{*}{ Variables } & \multicolumn{2}{|c|}{$\begin{array}{l}\text { Short-statured women } \\
\qquad(n=56)\end{array}$} & \multicolumn{2}{|c|}{$\begin{array}{l}\text { Non-short-statured } \\
\text { women }(n=57)\end{array}$} & \multirow[t]{2}{*}{$\begin{array}{l}\mathrm{P}- \\
\text { value }\end{array}$} \\
\hline & $\begin{array}{l}\text { Mean or } \\
\text { "Frequency" }\end{array}$ & $\begin{array}{l}\text { SD or } \\
\text { "\%" }\end{array}$ & $\begin{array}{c}\text { Mean or } \\
\text { "Frequency" }\end{array}$ & $\begin{array}{l}\text { SD or } \\
\text { "\%" }\end{array}$ & \\
\hline Age $(\text { years })^{1}$ & 32.39 & 6.58 & 30.47 & 6.61 & 0.12 \\
\hline Schooling (years) ${ }^{1}$ & 5.64 & 3.37 & 7.61 & 3.34 & $<0.01$ \\
\hline Total wage (US\$) ${ }^{1}$ & 381.81 & 233.06 & 437.77 & 255.66 & 0.23 \\
\hline Wage per capita $(\mathrm{US} \$)^{1}$ & 94.77 & 73.64 & 112.94 & 72.26 & 0.19 \\
\hline Number of children ${ }^{1}$ & 2.76 & 1.39 & 2.15 & 1.28 & 0.01 \\
\hline Rural origin ${ }^{2}$ & 31 & 55.3 & 12 & 21.1 & $<0.01$ \\
\hline Married/Stable union ${ }^{2}$ & 45 & 81.9 & 45 & 83.7 & 0.69 \\
\hline Unemployed $^{2}$ & 22 & 40.0 & 19 & 35.2 & 0.51 \\
\hline $\begin{array}{l}\text { Receive government } \\
\text { benefits }^{2}\end{array}$ & 46 & 83.6 & 39 & 72.2 & 0.09 \\
\hline Alcohol user ${ }^{2}$ & 18 & 32.7 & 15 & 27.8 & 0.49 \\
\hline Tobacco user $^{2}$ & 3 & 5.5 & 2 & 3.7 & 0.63 \\
\hline House with uncoated floor ${ }^{2}$ & 28 & 50.0 & 26 & 42.6 & 0.64 \\
\hline $\begin{array}{l}\text { House with uncoated } \\
\text { walls }^{2}\end{array}$ & 20 & 34.5 & 25 & 40.7 & 0.37 \\
\hline $\begin{array}{l}\text { Absence of sewage } \\
\text { system }^{2}\end{array}$ & 51 & 94.7 & 51 & 94.4 & 0.77 \\
\hline
\end{tabular}

${ }^{1}$ Results expressed as mean and standard deviation. 
${ }^{2}$ Results expressed as absolute and relative frequency.

2 


\section{Table 2 (on next page)}

Table 2. Anthropometric variables and self-body image perception of the sample ( $n=$ 113)

1P-value for the " $\mathrm{t}$ " tests for independent samples. 
1 Table 2. Anthropometric variables and self-body image perception of the sample $(\mathrm{n}=113)$.

\begin{tabular}{|c|c|c|c|c|c|}
\hline \multirow[t]{2}{*}{ Variables } & \multicolumn{2}{|c|}{$\begin{array}{l}\text { Short-statured women } \\
\qquad(\mathrm{n}=56)\end{array}$} & \multicolumn{2}{|c|}{$\begin{array}{l}\text { Non-short-statured } \\
\text { women }(\mathrm{n}=57)\end{array}$} & \multirow[t]{2}{*}{ P-value } \\
\hline & Mean & $\begin{array}{l}\text { Standard } \\
\text { deviation }\end{array}$ & Mean & $\begin{array}{l}\text { Standard } \\
\text { deviation }\end{array}$ & \\
\hline Weight (kg) & 71.46 & 10.07 & 85.59 & 15.32 & $<0.01$ \\
\hline Height $(\mathrm{cm})$ & 149.5 & 2.9 & 162.6 & 3.6 & $<0.01$ \\
\hline Body mass index $\left(\mathrm{kg} / \mathrm{m}^{2}\right)$ & 31.92 & 4.38 & 32.36 & 5.74 & 0.64 \\
\hline Body surface area $\left(\mathrm{m}^{2}\right)$ & 1.71 & 0.12 & 1.95 & 0.17 & $<0.01$ \\
\hline Body fat (\%) & 38.00 & 5.1 & 41.62 & 4.94 & $<0.01$ \\
\hline Fat mass $(\mathrm{kg})$ & 27.58 & 7.42 & 36.30 & 10.67 & $<0.01$ \\
\hline Lean mass $(\mathrm{kg})$ & 43.66 & 3.41 & 49.02 & 4.98 & $<0.01$ \\
\hline Basal Metabolic Rate (kcal/day) & 1463.6 & 106.5 & 1635.0 & 155.4 & $<0.01$ \\
\hline Waist circumference $(\mathrm{cm})$ & 94.18 & 10.22 & 97.90 & 12.66 & 0.09 \\
\hline Hip Circumference $(\mathrm{cm})$ & 107.80 & 8.67 & 114.50 & 10.94 & $<0.01$ \\
\hline Waist/Hip Ratio & 0.87 & 0.08 & 0.85 & 0.06 & 0.13 \\
\hline Waist/Height Ratio & 0.63 & 0.06 & 0.60 & 0.07 & 0.02 \\
\hline Current self-body image & 6.25 & 1.28 & 6.50 & 1.50 & 0.32 \\
\hline Ideal self-body image & 3.45 & 1.22 & 3.75 & 0.99 & 0.14 \\
\hline Discrepancy score & 2.80 & 1.55 & 2.75 & 1.59 & 0.86 \\
\hline
\end{tabular}

"P-value for the " $t$ " tests for independent samples. 


\section{Table 3(on next page)}

Table 3. Analysis of the anthropometric variables and basal metabolic rate adjusted by body weight $(n=113)$

1P-value for the ANCOVA using group as fixed fator and body weight as a covariate. 
1 Table 3. Analysis of the anthropometric variables and basal metabolic rate adjusted by body

2 weight $(\mathrm{n}=113)$

\begin{tabular}{|c|c|c|c|c|c|}
\hline \multirow[t]{2}{*}{ Variables } & \multicolumn{2}{|c|}{$\begin{array}{l}\text { Short-statured women } \\
\qquad(\mathrm{n}=56)\end{array}$} & \multicolumn{2}{|c|}{$\begin{array}{l}\text { Non-short-statured } \\
\text { women }(\mathrm{n}=57)\end{array}$} & $\begin{array}{c}\mathrm{P}- \\
\text { value }^{1}\end{array}$ \\
\hline & $\begin{array}{c}\text { Estimated } \\
\text { Marginal } \\
\text { Mean }\end{array}$ & $\begin{array}{c}\text { 95\% } \\
\text { Confidence } \\
\text { Interval }\end{array}$ & $\begin{array}{c}\text { Estimated } \\
\text { Marginal } \\
\text { Mean }\end{array}$ & $\begin{array}{c}95 \% \\
\text { Confidence } \\
\text { Interval }\end{array}$ & \\
\hline Fat mass $(\mathrm{kg})$ & 32.5 & $31.9-33.0$ & 31.4 & $30.9-31.9$ & $<0.01$ \\
\hline Lean mass $(\mathrm{kg})$ & 45.7 & $45.2-46.2$ & 46.9 & $46.4-47.4$ & $<0.01$ \\
\hline Body fat (\%) & 40.4 & 5.0 & 39.4 & 4.9 & 0.06 \\
\hline Basal metabolic rate (kcal) & 1534.9 & $1525-1543$ & 1565 & $1556-1573$ & $<0.01$ \\
\hline
\end{tabular}

$3{ }^{1} \mathrm{P}$-value for the ANCOVA using group as fixed fator and body weight as a covariate.

4 


\section{Table 4 (on next page)}

Table 4. Blood biochemical markers and blood pressure values of the sample $(n=113)$

HDL, high-density lipoprotein; LDL, low-density lipoprotein; HOMA-\%B, Homeostasis Model Assessment for $\beta$-cell function; HOMA-IR, Homeostasis Model Assessment for insulin resistance; $\mathrm{T} 3$, triiodothyronine; $\mathrm{T} 4$, thyroxine. ${ }^{2}$ Variables were subjected to Welch's t-test, due to unequal variances. ${ }^{b}$-value for the independent samples Student $t$-test, unless otherwise stated. 
1 Table 4. Blood biochemical markers and blood pressure values of the sample $(n=113)$

\begin{tabular}{|c|c|c|c|c|c|}
\hline \multirow[t]{2}{*}{ Variables } & \multicolumn{2}{|c|}{$\begin{array}{l}\text { Short-statured women } \\
\qquad(\mathrm{n}=56)\end{array}$} & \multicolumn{2}{|c|}{$\begin{array}{c}\text { Non-short-statured } \\
\text { women }(\mathrm{n}=57)\end{array}$} & \multirow[t]{2}{*}{ P-value ${ }^{b}$} \\
\hline & Mean & $\begin{array}{l}\text { Standard } \\
\text { deviation }\end{array}$ & Mean & $\begin{array}{l}\text { Standard } \\
\text { deviation }\end{array}$ & \\
\hline Glucose $(\mathrm{mmol} / \mathrm{L})^{\mathrm{a}}$ & 4.21 & 0.44 & 4.39 & 0.75 & 0.13 \\
\hline Total cholesterol (mmol/L) & 5.0 & 1.03 & 4.79 & 0.88 & 0.25 \\
\hline HDL-cholesterol $(\mathrm{mmol} / \mathrm{L})^{\mathrm{a}}$ & 1.24 & 0.20 & 1.26 & 0.27 & 0.66 \\
\hline LDL- cholesterol (mmol/L) & 3.09 & 0.84 & 2.83 & 0.75 & 0.08 \\
\hline Triacylglycerols (mmol/L) & 1.45 & 0.78 & 1.53 & 0.77 & 0.62 \\
\hline $\begin{array}{l}\text { Alanine amino-transferase } \\
(\mu \mathrm{kat} / \mathrm{L})^{\mathrm{a}}\end{array}$ & 0.33 & 0.15 & 0.41 & 0.31 & 0.10 \\
\hline $\begin{array}{l}\text { Aspartate amino-transferase } \\
(\mu \mathrm{kat} / \mathrm{L})\end{array}$ & 0.41 & 0.10 & 0.43 & 0.21 & 0.53 \\
\hline $\begin{array}{l}\text { Gamma-glutamyl transferase } \\
(\mu \mathrm{kat} / \mathrm{L})^{\mathrm{a}}\end{array}$ & 0.59 & 0.26 & 0.69 & 0.44 & 0.15 \\
\hline Albuminuria (mg/g cr) & 9.06 & 6.09 & 9.96 & 10.34 & 0.57 \\
\hline Cystatin-C (mg/L) & 0.67 & 0.11 & 0.68 & 0.11 & 0.70 \\
\hline $\begin{array}{l}\text { Thyroid-stimulating hormone } \\
\text { (mIU/L) }\end{array}$ & 1.66 & 0.87 & 1.74 & 0.34 & 0.67 \\
\hline Total-T3 (nmol/L) & 1.83 & 0.37 & 1.91 & 0.43 & 0.27 \\
\hline Total-T4 (nmol/L) & 120.2 & 22.77 & 128.4 & 21.49 & 0.04 \\
\hline Insulin $(\mathrm{pmol} / \mathrm{L})^{\mathrm{a}}$ & 57.23 & 11.32 & 67.16 & 12.15 & 0.09 \\
\hline HOMA-\%B & 156.26 & 64.16 & 163.81 & 70.79 & 0.55 \\
\hline HOMA-IR $^{\mathrm{a}}$ & 1.15 & 0.53 & 1.41 & 0.98 & 0.08 \\
\hline Systolic blood pressure (mmHg) & 123.27 & 15.21 & 122.65 & 12.92 & 0.81 \\
\hline Diastolic blood pressure (mmHg) & 76.75 & 11.30 & 74.70 & 10.06 & 0.31 \\
\hline
\end{tabular}

2 HDL, high-density lipoprotein; LDL, low-density lipoprotein; HOMA-\%B, Homeostasis Model

3 Assessment for $\beta$-cell function; HOMA-IR, Homeostasis Model Assessment for insulin

4 resistance; T3, triiodothyronine; T4, thyroxine.

5 aVariables were subjected to Welch's t-test, due to unequal variances.

6 bP-value for the independent samples Student $t$-test, unless otherwise stated. 


\section{Figure 1 (on next page)}

Scatterplot of the influence of BMI on current self-body image, stratified by groups.

Slopes differ signifcantly between groups $(Z=2.006 ; \mathrm{P}<0.05)$ 


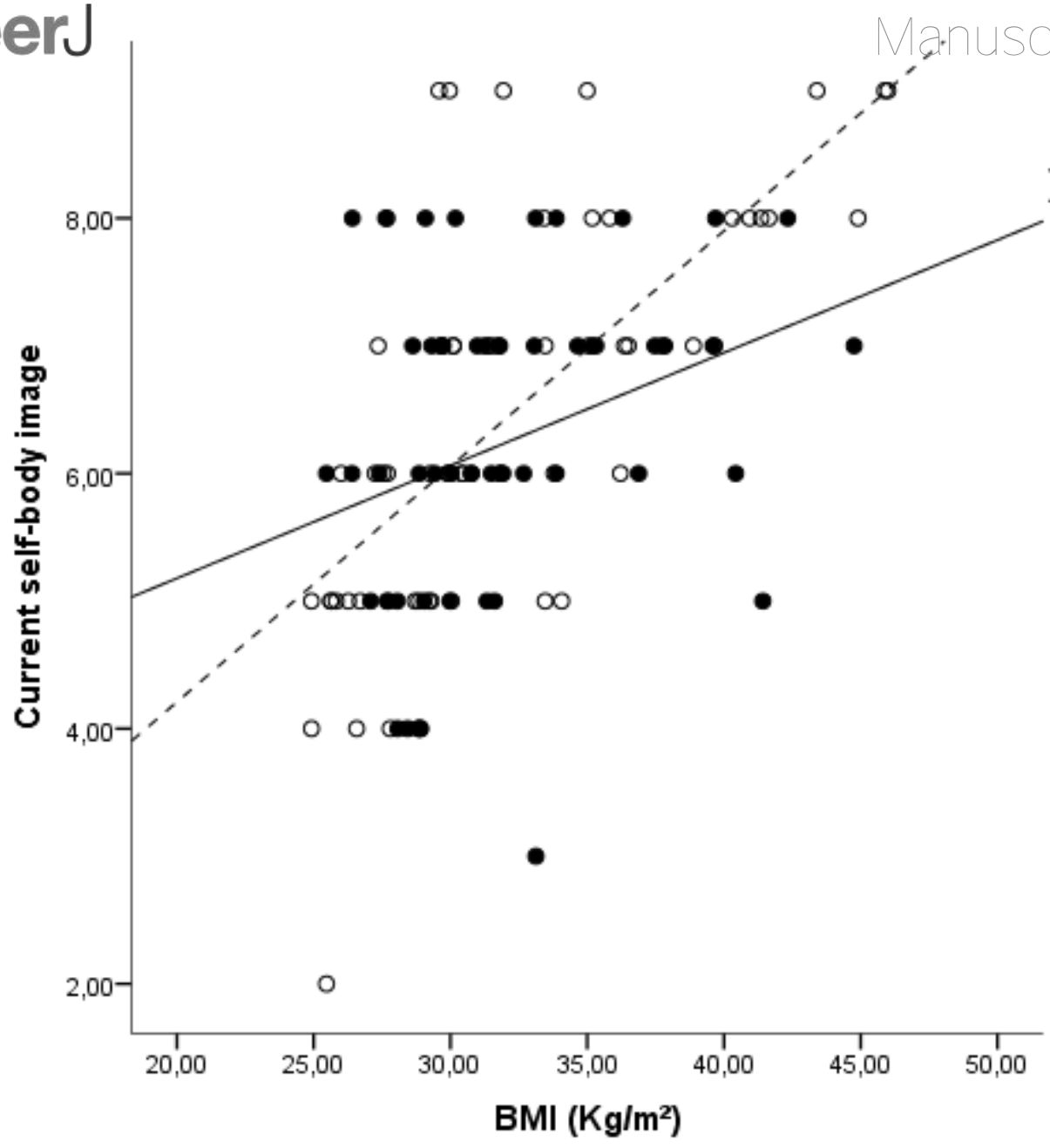

